\title{
Estimating travel times in dual shuttle AS/RSs.: A revised approach
}

\author{
Maurizio Schenone ${ }^{a}$, Giulio Mangano ${ }^{a}$, Sabrina Grimaldi ${ }^{a}$ and Anna Corinna Cagliano ${ }^{a}$
}

${ }^{a}$ Politecnico di Torino, Italy

\begin{tabular}{l}
\hline C H R O N I C L E \\
\hline Article history: \\
Received June 152018 \\
Received in Revised Format \\
November 62018 \\
Accepted December 72018 \\
Available online \\
December 72018 \\
\hline Keywords: \\
Dual Shuttle AS/RSs \\
Travel Time \\
Simulation \\
Regression Analysis
\end{tabular}

\begin{abstract}
A B S T R A C T
Automated Storage and Retrieval Systems (AS/RSs) effectively support warehouse operations in order to increase production and logistics efficiency. Literature about travel time computation in multi-shuttle AS/RSs still needs to be enhanced since most of the existing contributions rely on the same formulation, namely the Meller and Mungwattana's equation. Based on wellestablished theoretical assumptions and on a simulation model, the present work puts forward a revised version of the Meller and Mungwattana's formula for dual shuttle systems. In particular, the constant factor multiplying the travel between time is replaced by a coefficient depending on the rack configuration and on the input and output points of the storage system. The new equation is tested against widely applied models for AS/RS travel time calculation and proves to result in shorter times than the original Meller and Mungwattana's equation. A linear regression analysis is completed in order to find a numerical formulation of the proposed coefficient. Taking into account some key physical characteristics of a warehouse while estimating travel times allows improving the design and management of storage areas. Future research will focus on deepening multi-shuttle travel time calculation by addressing crane acceleration and deceleration, different rack and crane configurations, as well as class-based storage.
\end{abstract}

\section{Introduction}

In current competitive business environments keeping good inventories appropriately has become a key challenge for most industries (Jaggi et al., 2015) and this requires a careful warehouse design and management. Automated Storage and Retrieval Systems (AS/RSs) are warehousing systems widely applied to both distribution and production settings, especially in case of a large amount of products to store and high throughput rates. When associated with effective warehousing policies, they contribute to an accurate delivery of products (Choi et al., 2013). The basic components of AS/RSs are storage racks, input/output (I/O) stations, and storage/retrieval (S/R) machines, also named automated stacker cranes, with computerized control to store and retrieve warehouse stock without human help. Stacker cranes, which move along aisles between racks, pick incoming products from an I/O station and put them at specific storage locations. Then, they retrieve outgoing products from other locations and deliver them

* Corresponding author

E-mail: giulio.mangano@polito.it (G. Mangano)

2019 Growing Science Ltd.

doi: $10.5267 /$ j.ijiec.2018.12.002 
to the I/O station (Lerher et al., 2015). AS/RSs are frequently adopted due to their many advantages such as efficient utilization of warehouse space, reduced damages and loss of goods, increased control upon storage and retrieval operations, and decreased number of warehouse workers. They can be suitable for all the kinds of products, from very small electronic components to large car bodies, and all over the industrial chain, from raw material warehousing to final product distribution (Hamzaoui \& Sari, 2015). Optimal design and operations scheduling affect the performance of such systems (Cinar et al., 2017). As a matter of fact, good allocation and delivery times are important variables in warehouse management (Ma et al., 2015) in order to timely meet customer requirements in today's volatile markets (Jindal \& Solanki, 2016; Rabbani et al., 2016).

Several types of AS/RSs are available according to their physical configuration, namely the number and the potentiality of command of S/R machines, the location of racks and aisles, the position of the I/O station, the depth of racks, and the maximum number of products that can be placed in the same storage location (Ghomri \& Sari, 2015). On the one hand, based on stacker crane load capacity, single-shuttle and multi-shuttle systems can be recognized. The traditional single-shuttle design allows one unit load to be moved at a time. In multi-shuttle systems, cranes move more than one unit load during each cycle, typically two (dual or twin shuttle) or three unit loads (three shuttle). On the other hand, from an operational point of view S/R machines can perform both single command cycles and dual command cycles. Single command cycles are provided for either a storage or a retrieval task carried out between two consecutive visits of the I/O station. According to a dual command cycle, the S/R machine stores the first unit load, travels empty to a retrieval location, and picks the second unit load. Multi-shuttle $S / R$ machines execute multiple storage and retrieval operations in each cycle, with a consequent decrease in service time because of the reduced number of empty trips. The AS/RS service time is defined as the sum of the travel time of the S/R machine and the pickup/deposit time (Potrč et al., 2004).

One main feature of AS/RSs is their throughput rate because it determines the maximum number of unit loads that can be moved to and from the system in a given time unit. The throughput rate directly depends on the AS/RS service time, therefore estimating travel times plays a crucial role for designing AS/RSs. Extensive literature has been developed about travel times, especially for single-shuttle configurations. Conversely, multi-shuttle travel times are explored in a limited way and the existing contributions are mainly based on the model by Meller and Mungwattana (1997), which calculates the S/R machine cycle time as the sum of the cycle time for a single command cycle and the travel between time multiplied by a constant value. The travel between time is defined as the empty travel time of the stacker crane between two consecutive storage and retrieval locations. The above mentioned constant value does not depend on warehouse characteristics, although appropriate estimates of travel times should not neglect the structural features of the warehouses and the associated material handling equipment.

With the aim of contributing to bridge such a research gap, the present work revisits Meller and Mungwattana (1997)'s model for the case of dual shuttle systems, Quadruple-Command Cycles (QCs), and single-deep racks. In particular, it puts forward a new formulation of the coefficient multiplying the travel between time as a function of the rack shape factor and the $\mathrm{I} / \mathrm{O}$ station position. A mathematical equation for such a coefficient is proposed and consequently the travel time is simulated for different warehouse configurations. Results are compared with those obtained by applying the standard Meller and Mungwattana's formula in the same operational conditions. Simulation outcomes are also used as part of a regression analysis in order to develop a numerical formula allowing computing the coefficient.

The paper is structured as follows. First, in Section 2 mainstream literature on AS/RS travel time models is reviewed. Then, Section 3 and Section 4 respectively present the assumptions and the methodology used to develop the new travel time computation model, while Section 5 and Section 6 discuss simulation, the associated results, and the regression analysis. Finally, Section 7 addresses benefits, implications, limitations of the work, and future research directions, as well as draws conclusions. 


\section{Literature Review}

The pickup/deposit time is usually not taken into account while estimating the AS/RS service time, which is thus approximated by the $\mathrm{S} / \mathrm{R}$ machine travel time. This last amount of time has been extensively debated in literature since the 1970s (Graves et al., 1977; Hausman et al., 1976; Schwarz et al., 1978) and it has become a key parameter for the optimal design and for evaluating the performance of automated warehouses (Hur et al., 2004). Travel time studies can be classified in two broad categories according to the kind of AS/RS addressed: single-shuttle models and multi-shuttle models, with particular attention to dual-shuttle configurations. In this field both analytical and simulation models have been presented as discussed in the next subsections.

\subsection{Single-shuttle Travel Time Models}

Following the first contributions of the Seventies, the main reference for AS/RS single shuttle travel time estimate is the model developed by Bozer and White (1984). Their work proposes a travel time formulation for both single and dual command cycles by assuming racks continuous and rectangular in time, stacker cranes simultaneously moving in both the horizontal and vertical direction, constant horizontal and vertical speeds, and randomized storage assignment. Different storage rack shapes, I/O locations, and dwell-point strategies are analysed. Although its wide applicability, the Bozer and White's model does not allow for class-based storage policies. Lots of studies have been developed based on this contribution: the most relevant ones are here reviewed. Most of the pieces of research are concerned with traditional unit load AS/RSs. Among them, Peters et al. (1996) assess by means of analytical models the impact of different dwell point and I/O station positions on the stacker crane response time. A number of authors extend the Bozer and White (1984)'s formulation to take into account specific operational characteristics of an S/R system. In particular, Hwang and Lee (1990) put forward an analytical travel time model that includes both the maximum speed of a crane and the time required to reach such peak speed or to come to a halt. Chang et al. (1995) add to the Bozer and White's work stacker crane acceleration and deceleration rates instead of assuming a constant speed. A similar hypothesis is also later considered by Lerher et al. (2010a) while studying aisle transferring S/R machines. Based on the work of Chang et al. (1995), Wen et al. (2001) focus their travel time model on class-based and fullturnover-based storage assignment policies for single command cycles. Their model relies on the warehouse shape factor and the I/O station is set at the lower left corner of an aisle. Finally, Lerher et al. (2010b) propose a model for computing the travel time of unit load double-deep AS/RSs, while Lerher et al. (2015) calculate travel times for shuttle-based AS/RSs under uniform distributed storage rack locations.

Several AS/RS configurations have been developed over the years and appropriate travel time models have been presented as well. Hu et al. (2005) deal with a new kind of S/R machine able to efficiently handle heavy loads such as sea container cargos. In particular, they develop a continuous, single command travel time model by using the stay dwell point policy, that is a platform remains where it is after completing an S/R operation. Moreover, the rack shape factor is considered and the $\mathrm{I} / \mathrm{O}$ station is located on the ground level at the end of the rack. Fukunari and Malmborg (2008) address AS/RSs equipped with autonomous vehicles and suggest a model to compare their cycle time with that of cranebased AS/RSs. 3D compact AS/RSs are the topic of the research by Yu and De Koster (2009) who derive the mean single command cycle time with a full-turnover-based storage policy. In recent years flow rack AS/RSs have been analysed by Ghomri and Sari (2015) and Hamzaoui and Sari (2015). The first contribution looks at a storage system with a large number of product types and computes the associated average retrieval time as a function of the rack shape factor. The pickup station is located in the low left corner and the final end of the restoring conveyor in the low right corner of the storage structure. The second contribution finds the optimal size of single machine flow rack AS/RSs in order to minimize the expected travel time. 


\subsection{Multi-shuttle Travel Time Models}

While most of the research on travel times focuses on single shuttle systems, literature for multi-shuttle systems, and in particular dual and three shuttle, is very limited and it is mostly based on the work by Meller and Mungwattana (1997). Such authors put forward analytical travel time models for quadruple and sextuple command cycles with First Come First Served, nearest-neighbour, and reverse nearestneighbour storage strategies as well as constant velocity of the S/R machine. They show how the nearestneighbour policy enables to reduce the total travel time. Their analysis is based on the rack shape factor and an I/O station located in the lower left-hand corner of the storage structure. Potrč et al. (2004) extend the Meller and Mungwattana's equation by means of a heuristic travel time model under storage cells of equal height and a randomized storage policy. Both single and multi-shuttle configurations are taken into account. They also investigate the relationship between travel time and throughput rate for different rack types and stacker crane velocities. Their study proves that multi shuttle systems allow a significant improvement in throughput performance compared with single shuttle ones. De Puy (2007) introduces $\mathrm{S} / \mathrm{R}$ machine acceleration and deceleration in the Meller and Mungwattana's travel time model by finding a more complex formulation that however better represents real-life storage systems. In addition, Azzi et al. (2011) propose an alternative approach to Meller and Mungwattana's, which is based on the Federation Européenne de la Manutention (F.E.M.) 9851 standard to assess the throughput rate of dualshuttle AS/RSs. Monte Carlo simulations are conducted to both estimate travel times and compare the obtained results with those coming from alternative methods already existing in literature. Recently, $\mathrm{Xu}$ et al. (2015) propose the application of the Meller and Mungwattana's model to double-deep racks that having lower number of aisles, are considered more efficient. In their study, it is assumed random storage policy and travel times are computed using the fixed coefficient equal to 3 . Some studies on travel times of multi-shuttle systems are also related to mini-load AS/RSs. In this field, the works by Lerher et al. (2011), Oser and Garlock (1998), and Oser and Ritonja (2004) can be mentioned.

Finally, some comparisons between single-shuttle and multi-shuttle systems are available in literature. Guo and Liu (2008) adopt the simulation approach for such a purpose and state that dual-shuttle systems are likely to achieve higher performance when the following conditions are satisfied: the I/O stations are located at opposite ends, the time periods of storage/retrieval operations do not overlap, or there are significant batch demands. Keserla and Peters (1994) study and compare the performance of single and dual-shuttle AS/RSs under the nearest-neighbour retrieval-sequencing heuristic in order to minimize the travel time in a QC. Based on the performed review of exiting literature it comes up that unlike singleshuttle AS/RSs, the analysis of travel times in multi-shuttle configurations is still a poorly developed field and it deserves further attention. In particular, the available contributions usually stick with the formulation by Meller and Mungwattana (1997), which calculates the expected cycle times for both QCs and sextuple-command cycle (STCs) by summing the cycle time for a single command cycle with a multiple of the travel between time. This second quantity is computed as the travel between time multiplied by a constant value independent from the warehouse characteristics. However the travel time of S/R machines is a key parameter for an efficient warehouse (Ghomri \& Sari, 2015), because the time taken to store and retrieval products influences the schedule of warehouse activities and thus the time and cost behaviour of the overall system (Hwang \& Lee, 1990; Lerher et al., 2010a; Ma et al., 2015). Therefore, in order to obtain appropriate estimates of travel times, they should be directly related to the physical characteristics of warehouse spaces and of their material handling equipment so that to understand the role of the warehouse structure in determining its performance (Gu et al., 2010). With the aim of contributing to the growth of the literature on travel time models for dual-shuttle systems by taking into a greater account the operational characteristics of storage systems, as it already happens for single-shuttle configurations, the present work revises Meller and Mungwattana (1997)'s model for the case of QCs. In particular it studies how the constant coefficient multiplying the travel between time can be replaced by a variable depending on the rack shape factor and the I/O station position, which are two of the most relevant parameters associated with warehouse physical characteristics that impact on travel time models as highlighted in this section. 


\section{Model Assumptions}

The optimization of AS/RSs performance is a large domain of study and it includes the design, the dimensioning, the storage policies, the utilisation rate, and the cycle time. Thus, it appears to be crucial the definition of the environment of application for the model under analysis. In particular, the authors refer to dual shuttle AS/RSs that carry two unit loads at a time. This, implies that it is possible to perform more than one operation at a time. The increased number of storage and retrieval operations performed during one trip leads to a reduced empty travel time and consequently to higher operational efficiency (Yang et al., 2015). In the proposed model combined cycles are applied. As a matter of fact, not only the structural and operational characteristics of AS/RSs contribute to define the whole system performance, but also the command type plays a crucial role too (Guo \& Liu, 2008; Sarker \& Babu, 1995). In particular, for dual shuttle AS/RSs the possible configurations are: Double Single-Command Cycle (DSC) and Quadruple-Command Cycle (QC). In the case of QC the assumptions related to the best combination of storage and retrieval activities are considered: among the different possible routes, the proposed model relies on the combination that minimizes the travel time. This assumption implies that both input and output points have to be consecutive, meaning that the two storage stops $\left(\mathrm{I}_{1}\right.$ and $\left.\mathrm{I}_{2}\right)$ are performed before the two retrieval ones $\left(\mathrm{O}_{1}\right.$ and $\left.\mathrm{O}_{2}\right)$ as shown in Fig. 1.
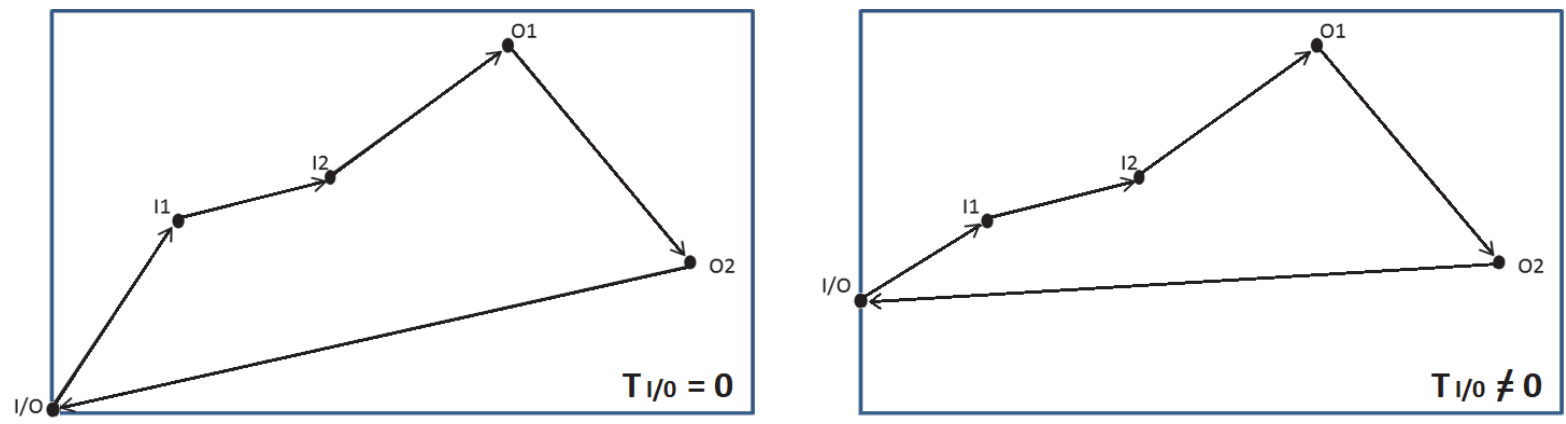

Fig. 1. Quadruple Command Cycle

In order to define all the remaining features of the model the authors mainly refer to the assumptions (Hi) given by Gagliardi et al. (2012). These are conveniently classified into three different groups according to the different AS/RS options (Roodbergen \& Vis, 2009): crane, rack and handling policy.

\section{Crane group}

- Cranes have independent drives on both axes, allowing them to travel horizontally and vertically simultaneously (i.e. travel time follows a Chebyshev distance metric) (H2).

- Crane acceleration and deceleration are assumed instantaneous and they are not considered in the analysis (H6).

- A single crane serves a single two-sided aisle (H8).

\section{$\underline{\text { Rack group }}$}

- The system is a unit-load AS/RS and each pallet holds only one part number or item type (H1).

- Single-deep racks are considered.

- All storage locations have the physical capability to store any item (H3).

- The distance (i.e. travel time) from rack location i to rack location i' is symmetrical and does not change over time (H5).

- The rack is considered to be continuous and rectangular-in-time (H13).

- The length measured in seconds of the warehouse is greater that the height.

- Rack utilisation is $100 \%$ (H16).

- The number of pallets in the system is constant (H26).

Handling policy group

- In the studied configurations the I/O station has the same initial horizontal value but different vertical ones (different elevations) (Bozer and White, 1984). 
- Pickup and storage times are assumed constant and they are not taken into account in the analysis (H7).

- A Pure Random Storage policy is used, then each product is stored anywhere in the racks (H15).

- Each I/O point is capable of serving both storage and retrieval requests (H19).

- Each pallet of an item has an equal probability of being selected during both storage and retrieval (H28).

\section{Methodology}

The research has been conducted through the following steps. First, based on the assumptions previously presented in Section 3, a simulator is developed by building up a macro in Microsoft Excel. Then simulations are run with the aim of evaluating travel times. Accordingly, twenty tests have been completed and for each test 1,000 computations have been carried out so that to obtain a stabilization of the error. Simulations have been completed for different levels of the I/O point $\left(T_{i / o}\right)$ associated with different values of the time needed to get the furthest column ( $\left.T_{\text {height }}\right)$. For each test the average value of the ratio of the travel time (T) over Tmax (see Eq. 4) is considered and results have been compared with the formulas of Meller and Mungwattana (1997) and Bozer and White (1984). This ratio allows an evaluation of the travel time that is not strictly related to the size of the warehouse space under analysis. If the storage and the retrieval operations are performed sequentially, the expected travel time (E(QC)) is equal to the expected time for a single command cycle $(\mathrm{E}(\mathrm{SC}))$ plus three times the travel between time $(\mathrm{E}(\mathrm{TB}))$ as reported in Eq. (1) provided by Meller and Mugwattana (1997).

$$
\begin{aligned}
& E(Q C)=E(S C)+3 E(T B), \\
& E(S C)=T_{\max } \times\left(1+1 / 3 b^{2}\right)+2 T_{\text {fixed }}, \\
& E(T B)=T_{\max } \times\left(1 / 3+1 / 6 b^{2}-1 / 30 b^{3}\right),
\end{aligned}
$$

where

$$
T_{\max }=\max \left(T_{\text {height }}, T_{\text {length }}\right),
$$

and $b$ is defined as the shape factor and it is equal to

$$
B=\min \left(T_{\text {height }} / T_{\max }, T_{\text {length }} / T_{\max }\right) \text {, }
$$

$\mathrm{T}_{\text {length }}$ is the time that is required to get the furthest rows and $\mathrm{T}_{\text {fixed }}$ is mainly given by the centring and the cycle time of the crane forks. The expected travel time in case of a $T_{i / o}$ that differs from 0 needs to be adjusted as follows:

$$
\begin{aligned}
& E(S C)=T_{\max } \times\left[1+1 / 3 h_{\text {hor }}{ }^{2}-d\left(h_{\text {hor }}-d\right)\right]+2 T_{\text {fixed }}, \\
& h_{\text {hor }}=T_{\text {height }} / T_{\text {length }}, \\
& d=T_{i / o} / T_{\text {length. }}
\end{aligned}
$$

This formula is true under the two following conditions:

$$
\begin{array}{ll}
d<1 & \left(T_{i / o}<T_{\text {length }}\right), \\
h_{\text {hor }}-d<1 & \left(T_{\text {height }}-T_{i / o}<T_{\text {length }}\right),
\end{array}
$$

In the case of a system with different values of $T_{i / o}$ the final equation that can be easily obtained, including the ratio between $E(Q C)$ and $T_{\text {max }}$, is:

$$
E(Q C) / T_{\max }=\left[T_{\max } \times\left(1+1 / 3 h_{h o r}\right)^{2}-\left(h_{h o r}-d\right)+3 \times T_{\max }\left(1 / 3+1 / 6 b^{2}-1 / 30 b^{3}\right)\right] / T_{\max } .
$$


As suggested by H7, $\mathrm{T}_{\text {fixed }}$ has not been taken into account, since it is a constant and it does not influence the output of the analysis. Then, benchmark with the equation by Meller and Mungwattana (1997) has been carried out in order to point out the limitations of that formula in the computation of travel time for dual shuttle systems, especially with regard to the coefficient 3 . In addition, a coefficient $K$ has been computed with the aim of replacing the fixed coefficient 3 of the formula of Meller and Mungwattana with a parameter that changes together with the main characteristics of the warehouse. Finally, assuming $K$ as the response variable, a linear regression analysis has been completed in order to get a numerical expression connecting $K$ to both $b$ and $\mathrm{T}_{\mathrm{i} / \mathrm{o}}$, the parameters representing the crucial characteristics of a warehouse.

\section{Description of the Simulator}

Simulation allows generating different scenarios in order to develop a comprehensive knowledge of the system under analysis. It is a well-known technique for investigating dynamic processes in complex and uncertain environments (Jansen et al., 2001). Furthermore simulation models a system in order to predict its operational performance and behaviour arising from particular conditions (Cagliano et al., 2017). In the present study the simulator has been developed by building a macro in Microsoft Excel that, based on four different random points, is able to identify the sequence of storage and retrieval operations minimizing the cycle time, as shown in Fig.1. The simulator is composed with two Excel workbooks, namely "Data Generation", wherein input and output data are shown, and "Data Elaboration" that runs simulations. Table 1 shows how the simulator computes the best route minimizing the travel time after the random generation of points. $\mathrm{x}(\mathrm{P})$ and $\mathrm{y}(\mathrm{P})$ are the time coordinates of a random point in the storage area when the origin of the coordinate system is set in the lower left corner. $\mathrm{T}_{1}(\mathrm{P})$ is equal to $\mathrm{x}(\mathrm{P})$, while $T_{h}(P)$ equals $y(P)$ minus $T_{i / o}$. The difference between $y(p)$ and $T_{h}(P)$ is due to the value of $T_{i / o}$ that in the example presented in Table 1 is equal to $10 \mathrm{~s}$. $\mathrm{T}_{\mathrm{h}}(\mathrm{P})$ can be expressed by the following formula: $\left|y(P)-T_{i / o}\right|$. For each iteration four points are identified: two of them are input points and two are output points. When $\mathrm{T}_{\mathrm{i} / \mathrm{o}}$ is $0 \mathrm{~T}_{\text {height }}(\mathrm{P})$ equals $\mathrm{T}_{\text {length }}(\mathrm{P})$. Once the points are set, the simulator computes the travel times between them for the different combinations and selects the one with the shortest total travel time. In the configuration shown in the example in Table $1 \boldsymbol{P}_{2} \boldsymbol{P}_{\mathbf{1}} \boldsymbol{P}_{3} \boldsymbol{P}_{4}$ is the combination that minimizes the travel time. Some examples of generated routes are also provided in Table 1.

Table 1

Generation of points and computation of times [s]

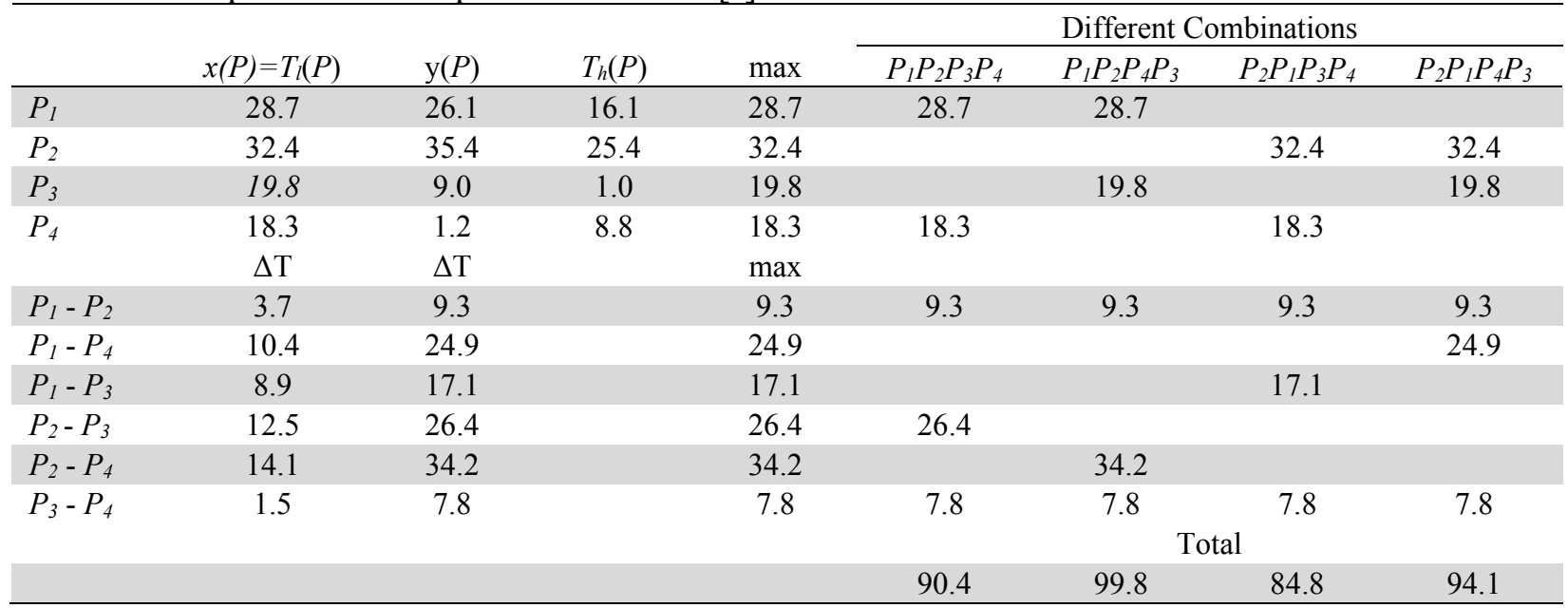

The simulator allows the random data generation once the input parameters are set. These are respectively:

- Value of the shape factor $b^{*}=T_{\text {length }} / T_{\text {height }}$, where 
$\circ \mathrm{b}^{*}=1 / \mathrm{b}$ if $\mathrm{T}_{\text {length }}>\mathrm{T}_{\text {height }}$

$\circ \mathrm{b}^{*}=\mathrm{b}$ if $\mathrm{T}_{\text {length }}<\mathrm{T}_{\text {height }}$

- Number of iterations.

- Input/output time $\left(\mathrm{T}_{\mathrm{i} / \mathrm{o}}\right)$.

- Vertical time $\left(\mathrm{T}_{\text {height}}\right)$.

- Horizontal time $\left(\mathrm{T}_{\text {length }}\right)$.

Simulations are run under the following conditions:

- The shape factor $b^{*}$ ranges from 1 to 2 with steps equal to 0.2 .

- Each simulation is composed by 1,000 iterations.

- Different $\mathrm{T}_{\mathrm{i} / \mathrm{o}}$ values are taken into account: $0,10 \%, 20 \%, 30 \%, 40 \%$, and $50 \% \mathrm{~T}_{\text {height. Values greater }}$ than $50 \% \mathrm{~T}_{\text {height }}$ are not included in the analysis since they are symmetrical to the ones already considered.

- $\quad T_{\text {height }}$ is obtained through the equation for computing $b^{*}$.

As a first validation, the proposed simulator has been tested through a benchmark with the formula by Bozer and White (1984) (Eq. 12) in order to check its robustness for computing travel times in a singleshuttle configuration under both single and dual command cycles. This comparison has been completed with the aim of testing the validity of the results provided by the simulator against a formula that is broadly considered as reliable and robust.

$$
E(S C)=1 / 3 b^{2}+1
$$

The outputs resulting from the simulator compared with the ones obtained by the Bozer and White's formula are presented in Fig. 2.

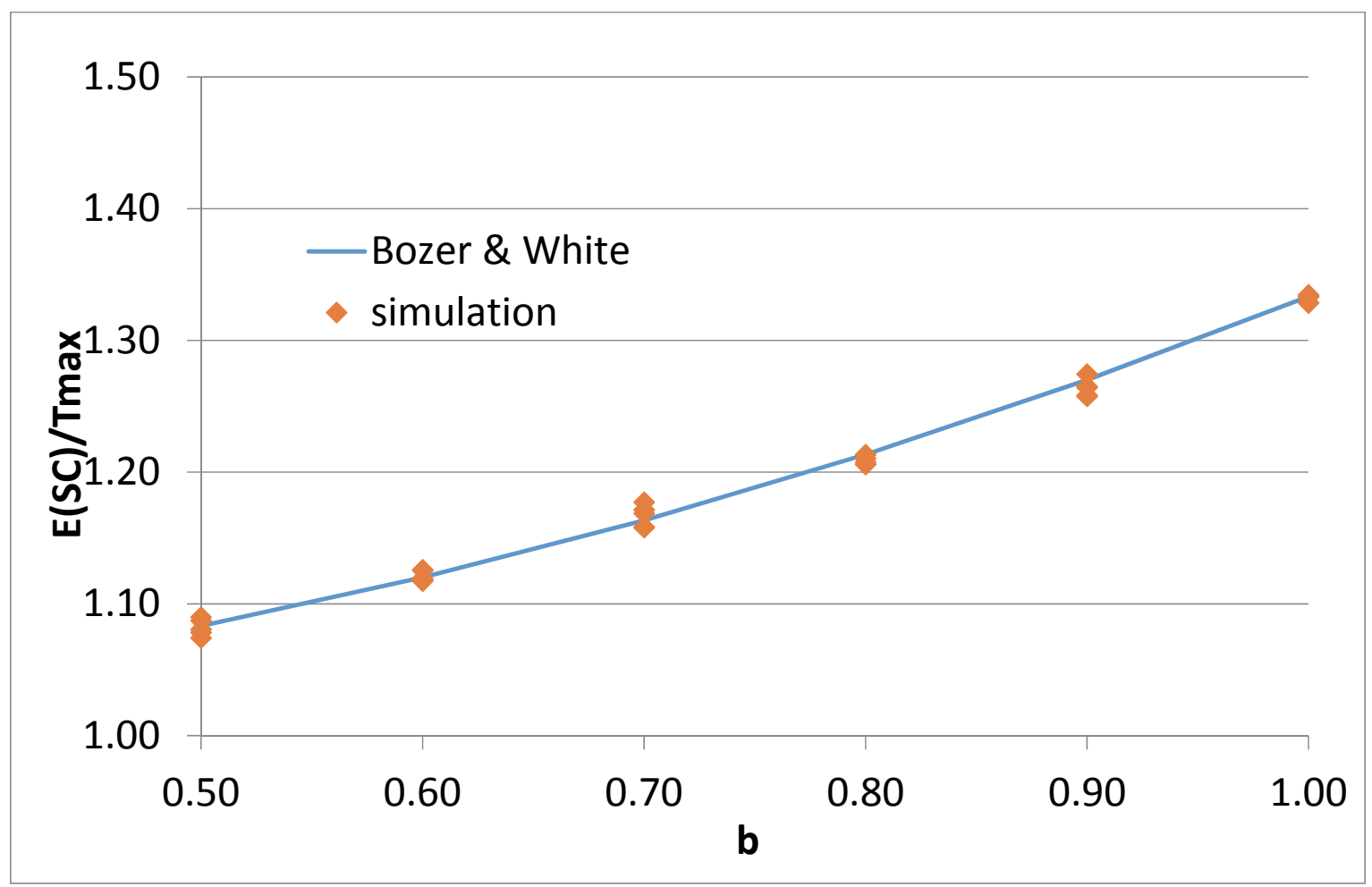




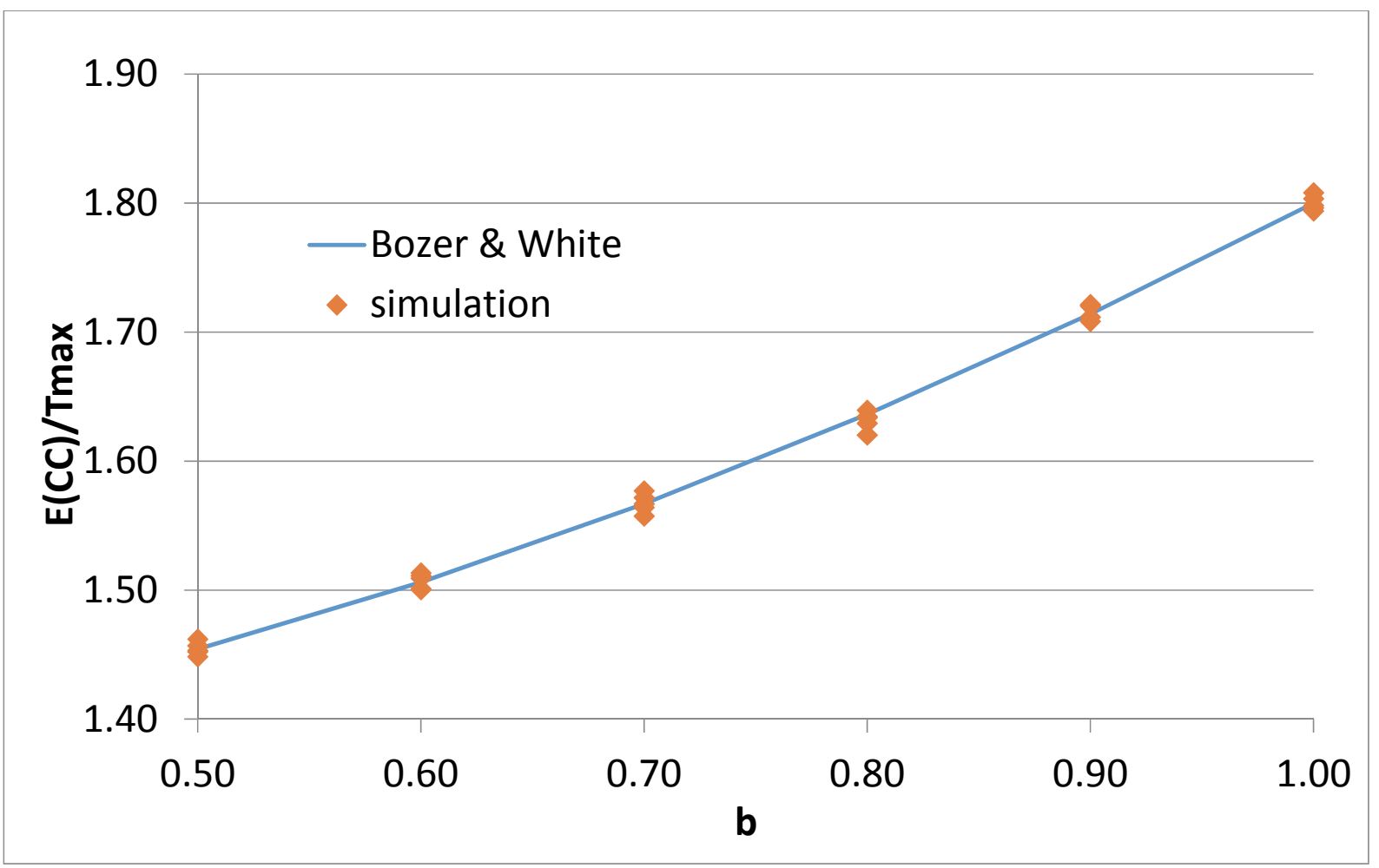

Fig. 2. Benchmark between the Bozer and White's formula and the simulator

These graphs summarize the results of two different kinds of simulation. The one shown on the left is related to a single command cycle while the one displayed on the right addresses a dual command cycle. Such simulations have been computed with the same system configuration in terms of height, length, and $T_{i / o}$ that equals 0 as the initial configuration. The diagrams show that both the simulator and the Bozer and White's formula provide the same results for the two cycle types at issue. Therefore, the simulator is perfectly able to model and forecast the behaviour of an AS/RS based on the assumptions defined earlier in this section.

\section{Simulation Results}

For every defined warehouse configuration 20 simulations made of 1,000 random computations each has been performed and the average value of the resulting travel times has been calculated and compared with the one obtained by applying the equation provided by Meller and Mungwattana (1997). The identified configurations are six according to different $T_{\text {height }}$ values and simulations were run for six $T_{i / o}$ levels, from 0 to $50 \%$ in steps of $10 \%$. Therefore 720 simulations have been carried out. Table 2 summarizes simulation results with the different $\mathrm{T}_{\mathrm{i} / \mathrm{o}}$ values. During the first group of simulations this parameter is set to 0 then $10 \%(0.1), 20 \%(0.2), 30 \%(0.3), 40 \%(0.4)$ and finally, $50 \%(0.5)$ of $\mathrm{T}_{\text {height. }}$ A new variable, named $\mathrm{q}$, has been also defined as follows:

$$
q=T_{i / o} / T_{\text {height. }}
$$

Such a variable represents $T_{i / o}$ expressed as a percentage. In this way it is possible to carry out computations without using the actual size of the warehouse, by taking into account just the defined ratio. The columns in Table 2 report respectively the time in length and height ( $\mathrm{T}_{\text {length }}$ and $\left.\mathrm{T}_{\text {height }}\right), \mathrm{T}_{\mathrm{i} / \mathrm{o}}$, the $\mathrm{T} / \mathrm{T}_{\max }$ values out of simulations, their average value, the results provided by the Meller and Mungwattana's formula, and the difference between the travel time calculated through the proposed methodology and the travel time computed through the Meller and Mungwattana's equation. Simulation results and the outcomes of the Meller and Mungwattana's formula are compared in Fig. 3. It is important to highlight that the travel times obtained through simulation are always shorter than the travel times 
calculated by the Meller and Mungawattana's approach. This means that actually the formula by Meller and Mungawattana overestimates the service travel times.

Table 2

Results of simulations

\begin{tabular}{|c|c|c|c|c|c|c|c|c|c|c|c|}
\hline $\mathbf{b}^{*}$ & $\mathbf{q}$ & $\begin{array}{c}\mathrm{Tl} \\
\text { lenght (s) }\end{array}$ & $\begin{array}{c}\text { Th } \\
\text { height (s) }\end{array}$ & $\begin{array}{c}\mathrm{Ti} / \mathrm{o} \\
(\mathrm{s})\end{array}$ & $\begin{array}{l}T / T_{\max } \\
\operatorname{Sim} \# 1\end{array}$ & $\begin{array}{l}T / T_{\max } \\
\text { Sim \#2 }\end{array}$ & $\cdots$ & $\begin{array}{c}T / T_{\max } \\
\text { Sim \#20 }\end{array}$ & $\begin{array}{c}\mathrm{T} / \mathrm{T}_{\max } \\
\text { Average Sim }\end{array}$ & $\begin{array}{c}\mathrm{E}(\mathrm{QC}) / \mathrm{T}_{\max } \\
\text { Mel\&Mun }\end{array}$ & $\begin{array}{c}\Delta t / T_{\max } \\
(\mathbf{M} \& M-S i m)\end{array}$ \\
\hline 1,0 & $\mathbf{0 , 0}$ & 50 & 50 & 0,0 & 2,2912 & 2,3029 & & 2,3050 & 2,402150 & 2,733333 & 0,331183 \\
\hline 1,2 & $\mathbf{0 , 0}$ & 50 & 42 & 0,0 & 2,1412 & 2,1493 & $\ldots$ & 2,1266 & 2,197111 & 2,520833 & $\mathbf{0 , 3 2 3 7 2 3}$ \\
\hline 1,4 & $\mathbf{0 , 0}$ & 50 & 36 & 0,0 & 2,0131 & 2,0087 & $\cdots$ & 2,0088 & 2,065000 & 2,388727 & 0,323727 \\
\hline 1,6 & $\mathbf{0 , 0}$ & 50 & 31 & 0,0 & 1,9210 & 1,9515 & $\ldots$ & 1,9346 & 1,976000 & 2,301107 & $\mathbf{0 , 3 2 5 1 0 7}$ \\
\hline 1,8 & $\mathbf{0 , 0}$ & 50 & 28 & 0,0 & 1,8392 & 1,8588 & $\ldots$ & 1,8608 & 1,904150 & 2,240055 & 0,335905 \\
\hline 2,0 & $\mathbf{0 , 0}$ & 50 & 25 & 0,0 & 1,8225 & 1,8258 & $\ldots$ & 1,8188 & 1,851900 & 2,195833 & 0,343933 \\
\hline 1,0 & 0.1 & 50 & 50 & 5,0 & 2,3138 & 2,2772 & $\ldots$ & 2,3088 & 2,305864 & 2,643333 & 0,337469 \\
\hline 1,2 & 0,1 & 50 & 42 & 4,2 & 2,1125 & 2,1071 & $\ldots$ & 2,1291 & 2,128168 & 2,461048 & 0,332880 \\
\hline 1,4 & 0,1 & 50 & 36 & 3,6 & 2,0225 & 2,0046 & $\ldots$ & 2,0148 & 2,009649 & 2,344803 & 0,335154 \\
\hline 1,6 & 0,1 & 50 & 31 & 3,1 & 1,9355 & 1,9172 & $\ldots$ & 1,9135 & 1,926067 & 2,264436 & 0,338369 \\
\hline 1,8 & 0,1 & 50 & 28 & 2,8 & 1,8539 & 1,8593 & $\ldots$ & 1,8634 & 1,857747 & 2,213484 & 0,355737 \\
\hline 2,0 & 0,1 & 50 & 25 & 2,5 & 1,8175 & 1,8402 & $\ldots$ & 1,8144 & 1,823129 & 2,173333 & 0,350204 \\
\hline 1,0 & 0,2 & 50 & 50 & 10,0 & 2,2271 & 2,2213 & $\ldots$ & 2,2323 & 2,231400 & 2,573333 & 0,341933 \\
\hline 1,2 & 0,2 & 50 & 42 & 8,4 & 2,0680 & 2,0793 & $\ldots$ & 2,0542 & 2,071550 & 2,411656 & 0,340106 \\
\hline 1,4 & 0,2 & 50 & 36 & 7,2 & 1,7585 & 1,9683 & $\ldots$ & 1,9487 & 1,949100 & 2,308515 & 0,359415 \\
\hline 1,6 & 0,2 & 50 & 31 & 6,2 & 1,8793 & 1,8766 & $\ldots$ & 1,8991 & 1,883800 & 2,237528 & 0,353728 \\
\hline 1,8 & 0,2 & 50 & 28 & 5,6 & 1,8293 & 1,8396 & $\begin{array}{l}\cdots \\
\ldots\end{array}$ & 1,8429 & 1,830250 & 2,191532 & 0,361282 \\
\hline 2,0 & 0,2 & 50 & 25 & 5,0 & 1,7940 & 1,7959 & $\ldots$ & 1,7884 & 1,790450 & 2,155833 & 0,365383 \\
\hline 1,0 & 0.3 & 50 & 50 & 15,0 & 2,2000 & 2,1936 & $\ldots$ & 2,1663 & 2,170164 & 2,523333 & 0,353169 \\
\hline 1,2 & $\mathbf{0 , 3}$ & 50 & 42 & 12,6 & 2,0311 & 2,0193 & $\ldots$ & 2,0288 & 2,026474 & 2,376376 & 0,349902 \\
\hline 1,4 & 0,3 & 50 & 36 & 10,8 & 1,9090 & 1,9263 & $\ldots$ & 1,9285 & 1,924940 & 2,282595 & 0,357655 \\
\hline 1,6 & $\mathbf{0 , 3}$ & 50 & 31 & 9,3 & 1,8580 & 1,8495 & $\ldots$ & 1,8457 & 1,854654 & 2,218308 & 0,363654 \\
\hline 1,8 & $\mathbf{0 , 3}$ & 50 & 28 & 8,4 & 1,8195 & 1,8072 & $\ldots$ & 1,8275 & 1,809987 & 2,175852 & 0,365864 \\
\hline 2,0 & 0,3 & 50 & 25 & 7,5 & 1,7706 & 1,7725 & $\ldots$ & 1,7833 & 1,769199 & 2,143333 & 0,374134 \\
\hline 1,0 & 0.4 & 50 & 50 & 20,0 & 2,1494 & 2,1478 & $\ldots$ & 2,1370 & 2,137195 & 2,493333 & 0,356138 \\
\hline 1,2 & 0,4 & 50 & 42 & 16,8 & 1,9901 & 1,9850 & $\ldots$ & 1,9882 & 1,994559 & 2,355208 & 0,360649 \\
\hline 1,4 & 0,4 & 50 & 36 & 14,4 & 1,9009 & 1,9253 & $\ldots$ & 1,8917 & 1,898924 & 2,267043 & 0,368119 \\
\hline 1,6 & 0,4 & 50 & 31 & 12,4 & 1,8319 & 1,8351 & $\ldots$ & 1,8561 & 1,837199 & 2,206776 & 0,369577 \\
\hline 1,8 & 0,4 & 50 & 28 & 11,2 & 1,7993 & 1,7996 & $\cdots$ & 1,8096 & 1,791422 & 2,166444 & 0,375021 \\
\hline 2,0 & 0,4 & 50 & 25 & 10,0 & 1,7639 & 1,7751 & … & 1,7571 & 1,760060 & 2,135833 & $\mathbf{0 , 3 7 5 7 7 3}$ \\
\hline 1,0 & 0,5 & 50 & 50 & 25,0 & 2,1423 & 2,1038 & $\ldots$ & 2,1367 & 2,126690 & 2,483333 & 0,356643 \\
\hline 1,2 & 0,5 & 50 & 42 & 21,0 & 1,9734 & 1,9974 & $\ldots$ & 1,9970 & 1,982283 & 2,348152 & 0,365869 \\
\hline 1,4 & 0,5 & 50 & 36 & 18,0 & 1,9024 & 1,9100 & $\ldots$ & 1,8805 & 1,894882 & 2,261859 & 0,366977 \\
\hline 1,6 & 0,5 & 50 & 31 & 15,5 & 1,8166 & 1,8330 & $\cdots$ & 1,8514 & 1,835761 & 2,202932 & 0,367171 \\
\hline 1,8 & 0,5 & 50 & 28 & 14,0 & 1,7947 & 1,7896 & $\cdots$ & 1,7993 & 1,789412 & 2,163308 & 0,373896 \\
\hline 2,0 & 0,5 & 50 & 25 & 12,5 & 1,7369 & 1,7324 & $\ldots$ & 1,7505 & 1,747154 & 2,133333 & 0,386179 \\
\hline
\end{tabular}

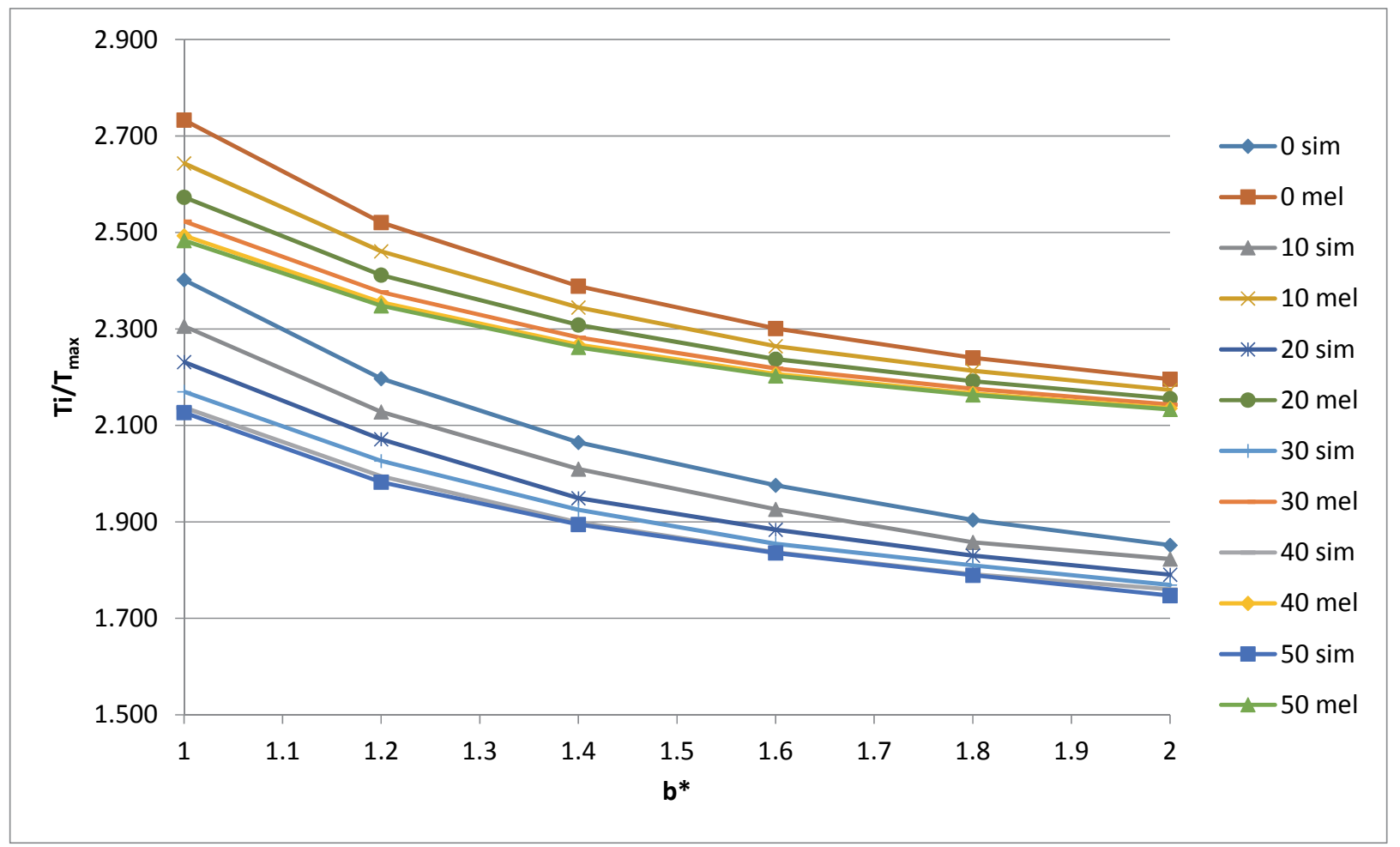

Fig. 3. Comparison between simulation and Meller and Mungwattana's formula 
The difference between the $\mathrm{T} / \mathrm{T}_{\max }$ values is almost the same for all the studied warehouse configurations and it ranges from 0.323 to 0.386 . Moreover it can be noticed that the higher $\mathrm{T}_{\mathrm{i} / \mathrm{o}}$, the higher the travel time gap resulting from the comparison. In order to get a better understanding about the behaviour of this gap, for each case a coefficient named $\boldsymbol{K}$ has been defined so that the result of the Meller and Mungwattana's formula equals the simulation output. $\boldsymbol{K}$ is computed with the aim of replacing the coefficient equal to 3 multiplying the travel between time in the equation by Meller and Mungwattana (1997) with a coefficient that is not fixed but it depends on the warehouse size (b) and on the I/O station position $\left(\mathrm{T}_{\mathrm{i} / \mathrm{o}}\right)$. $\boldsymbol{K}$ is calculated as per Eq. (14):

$$
\mathrm{E}(\mathrm{QC})=\mathrm{E}(\mathrm{SC})+\boldsymbol{K} \mathrm{E}(\mathrm{TB})
$$

Based on Eq. (3) and Eq. (6), it is possible to express Eq. (14) as a function of the coefficient $\boldsymbol{K}$ that replaces the factor 3 in the formula provided by Meller and Mungwattana (1997).

$$
\begin{aligned}
& E(Q C) / T_{\text {Max }}=\left\{T_{\text {Max }} \times\left[1+1 / 3 h_{\text {hor }^{2}}{ }^{2}-d \times\left(h_{\text {hor }}-d\right)\right]+\boldsymbol{K}^{*} T_{\text {Max }} \times\left(1 / 3+1 / 6 b^{2}-1 / 30 b^{3}\right)\right\} / T_{\text {Max }}, \\
& \mathbf{K}=\left\{\mathrm{T}(\operatorname{sim})-\mathrm{T}_{\operatorname{Max}} \times\left[1+1 / 3 \mathrm{~h}_{\text {hor }^{2}}{ }^{2} \mathrm{~d} \times\left(\mathrm{h}_{\text {hor }}-\mathrm{d}\right)\right]\right\} /\left[\mathrm{T}_{\operatorname{Max}} \times\left(1 / 3+1 / 6 \mathrm{~b}^{2}-1 / 30 \mathrm{~b}^{3}\right)\right],
\end{aligned}
$$

where $\mathrm{T}(\operatorname{sim})$ is the $\mathrm{E}(\mathrm{QC})$ value out of simulations and $\mathrm{T}_{\text {fixed }}$ is here ignored.

\begin{tabular}{|c|c|c|c|c|c|c|c|}
\hline & & \multicolumn{6}{|c|}{ q } \\
\hline & & 0.0 & 0.1 & 0.2 & 0.3 & 0.4 & 0.5 \\
\hline \multirow{6}{*}{$\mathbf{b}^{*}$} & 1.0 & 2.2903 & 2.2769 & 2.2673 & 2.2432 & 2.2368 & 2.2358 \\
\hline & 1.2 & 2.2468 & 2.2255 & 2.2087 & 2.1859 & 2.1609 & 2.1487 \\
\hline & 1.4 & 2.2031 & 2.1749 & 2.1152 & 2.1196 & 2.0938 & 2.0966 \\
\hline & 1.6 & 2.1670 & 2.1331 & 2.0937 & 2.0683 & 2.0531 & 2.0593 \\
\hline & 1.8 & 2.1138 & 2.0615 & 2.0469 & 2.0348 & 2.0106 & 2.0136 \\
\hline & 2.0 & 2.0725 & 2.0556 & 2.0147 & 1.9911 & 1.9867 & 1.9586 \\
\hline
\end{tabular}

Table 3

K values

Table 3 provides all the resulting values of $\boldsymbol{K}$ for the different levels of $b^{*}$ and $q$ that better refine the Meller and Mungwattana's original formula. The final objective is to figure out the relationship between $\boldsymbol{K}, \mathrm{b}^{*}$, and $\mathrm{q}$ that are the most important shape the parameters for a warehouse. Fig. 4 graphically represents the values of $\boldsymbol{K}$ reported in Table 3 in order to clearly display the relationship between $\boldsymbol{K}$ and the variables $b^{*}$ and $q$.

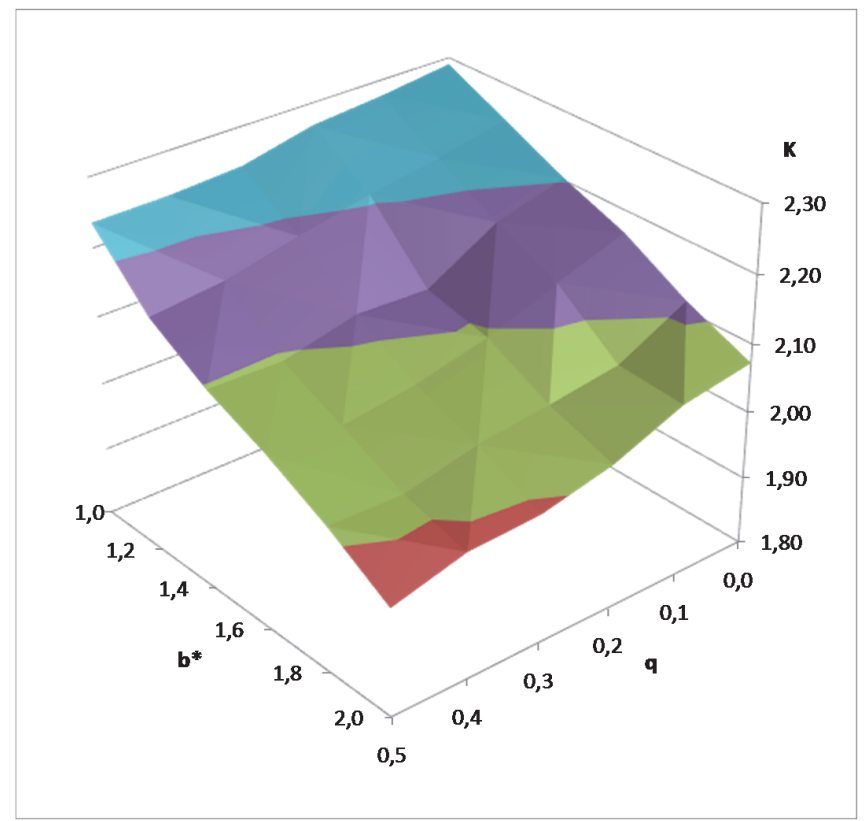

Fig. 4. The behaviour of $K$ 
At this stage a linear regression analysis has been performed, assuming that $\boldsymbol{K}$ is the response variable and $b$ and $T_{i / o}$ the independent factors. Such a regression model has been applied with the purpose of obtaining a numerical formulation for the coefficient $\boldsymbol{K}$. The regression analysis aims to test if the independent variables taken into account are significant factors and whether they have a negative or positive impact on the response or dependent variable (Tukey, 1977). A negative influence means that an increase (decrease) in the independent variable determines a decrease (increase) in the dependent variable. On the contrary, a positive influence indicates that the independent and response variable variations have the same sign. Linear regression analysis is a widely used tool for investigating relationships among variables within datasets (De Marco \& Mangano, 2011). The results of the performed regression analysis are shown in Table 4, where the columns report the estimate of the regression coefficient, the standard error of the estimate, the value of the $\mathrm{T}$ statistic, and the $\mathrm{p}$-value.

Table 4

Results of the regression analysis

\begin{tabular}{lcccc}
\hline Variable & Estimate & Std. Error & t-value & p-value \\
\hline $\mathrm{b}^{*}$ & -0.24215 & 0.0079 & -30.5100 & 0.00010 \\
$\mathrm{q}$ & -0.19677 & 0.0157 & -12.5100 & 0.00010 \\
Multiple R-Squared & $97.10 \%$ & & & \\
Adjusted R-Square & $96.90 \%$ & & & \\
Constant & 2.53590 & & & \\
\hline
\end{tabular}

The level of significance associated with the p-value, which ranges from 0 to 1 , represents the probability of incorrectly rejecting a null hypothesis. The smaller the p-value, the lower the probability that rejecting the null hypothesis is wrong. If it is less than a predetermined value, usually equal to $5 \%$, the null hypothesis is rejected. In the regression analysis the null hypothesis states that the estimate of the coefficient equals zero (Montgomery \& Runger, 1999). Results reveal that both $b^{*}$ and $q$ are significant factor of $\boldsymbol{K}$. This means that the warehouse shape and the I/O station position should be included in travel time calculation instead of merely considering a constant value multiplying the travel between time. This finding is very important and it allows a more precise computation of travel times for a dual shuttle system, because a couple of variables representing main warehouse physical characteristics are taken into account instead of just a constant number.

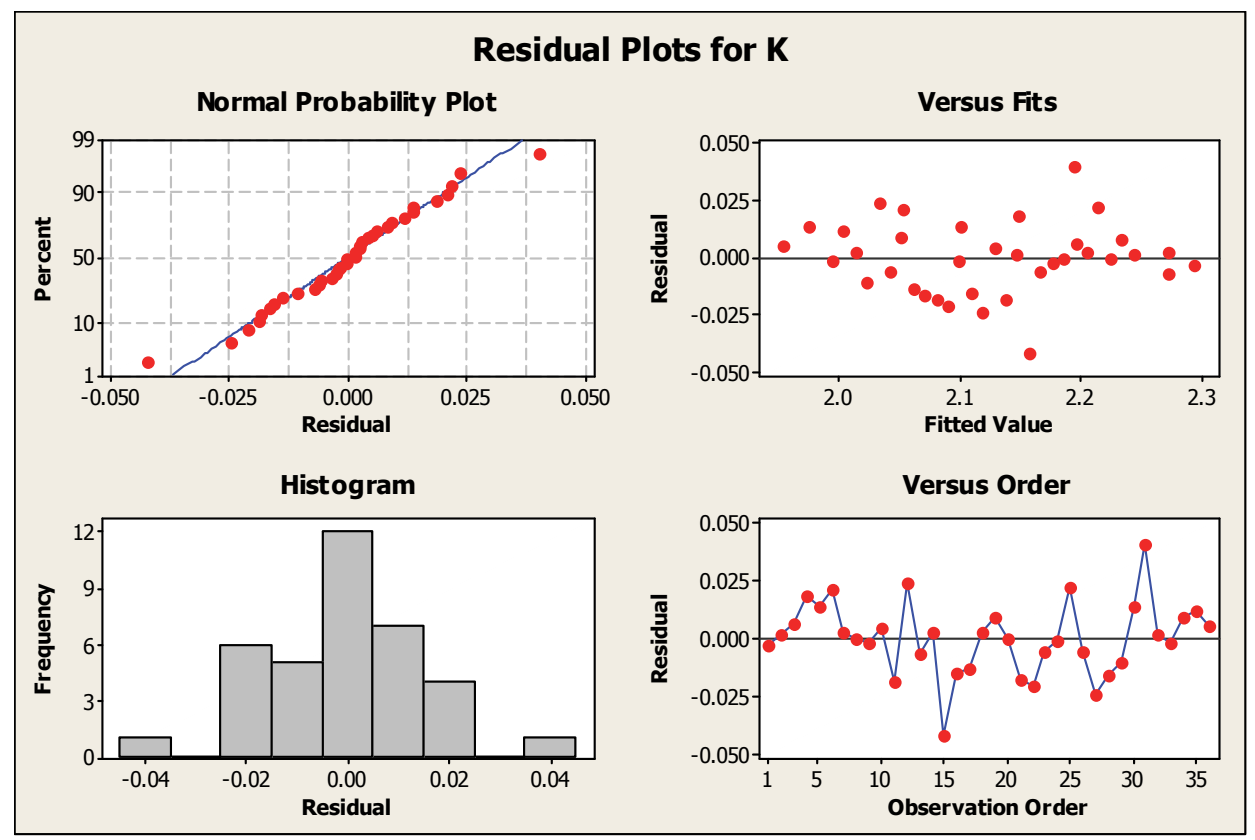

Fig. 5. Tests on the regression model 
Some tests in residuals are carried out to validate the regression model consistency (Fig. 5). In particular the Normal Probability Plot and the Histogram illustrate that residuals can be considered normally distributed; the Versus Fit graph indicates that there is no evidence of systematic error in the residuals and the Versus Order Graph does not show time series or periodicity.

Therefore the numerical formula that allows evaluating the $\boldsymbol{K}$ coefficient is:

$$
\boldsymbol{K}=2.53590-0.24215 \mathrm{~b}^{*}-0.19677 \mathrm{q}
$$

Similarly to Meller and Mungwattana's notation, the formula can be written as:

$$
\boldsymbol{K}=2.53590-0.24215 * 1 / \mathrm{b}-0.19677 \mathrm{q} .
$$

In this way, based on Eq. (14) and Eq. (15), the adjusted Meller and Mungwattana's formula can be defined as follows:

$$
\mathrm{T} / \mathrm{T}_{\mathrm{Max}}=1+1 / 3 \mathrm{~h}_{\text {hor }}^{2}-\mathrm{d}^{*}\left(\mathrm{~h}_{\text {hor }}-\mathrm{d}\right)+\left(2.54-0.24 \mathrm{~b}^{-1}-1 / 5 \mathrm{q}\right) *\left(1 / 3+1 / 6 \mathrm{~b}^{2}-1 / 30 \mathrm{~b}^{3}\right)
$$

\section{Discussions and Conclusions}

This paper has addressed dual shuttle AS/RSs with single-deep racks. In particular, its goal was to revise the Meller and Mungwattana's model (1997) by replacing the constant value equal to 3 multiplying the travel between time with a new coefficient $\boldsymbol{K}$ dependent on the warehouse shape factor and on the I/O station position. The proposed equation was based on a simulation model and allows a more precise travel time computation that takes into account some of the key physical characteristics of a warehouse implementing an automated storage system. The improvement in travel time evaluation also enabled a more accurate assessment of the throughput rate. The contribution brings a new perspective to the current literature on travel time estimate for multi-shuttle systems, which manly relies on the Meller and Mungwattana's equation (Potrč et al., 2004; De Puy, 2007). A more accurate calculation of travel times as a function of the rack configuration and of the input and output points of the storage system yields benefits to warehouse design and management, allowing to plan for the appropriate number and type of resources, improve the service level, and ultimately optimize costs. Additionally, the Excel-based simulation model, together with the numerical equation to compute the travel time, constitutes a straightforward tool that can be used to predict the AS/RS performance. The present work originates some theoretical and practical implications. From a theoretical point of view, the refined formula represents an improvement of a widely used methodology and it can be considered as a basis for further investigations about warehouse organization and the associated products to be stored. From a practical perspective, the obtained formula allows for a more precise computation of travel times in picking and delivery processes. A more correct travel time forecasting may bring significant benefits to an organization, which can carry out its warehouse operations more effectively, especially in terms of warehouse design and storage location assignment strategies. In particular, the proposed formula allows achieving lower service travel times than those calculated with the original Meller and Mungwattana's expression. This means that the throughput rate of a system can be increased and more unit loads can be managed in a given amount of time, or on the contrary a fixed number of unit loads can be handled with a reduced quantity of resources. Also, the model might support calculating AS/RS performance during feasibility studies and the first design phases. However, this work suffers from some limitations. In particular, acceleration and deceleration are not included in the study. Furthermore, class based storage areas are not considered. Thus, future research will be addressed to analyse AS/RSs based on different assumptions associated with cranes, racks, and handling policies. In particular the authors are planning to take into account both crane acceleration and deceleration and a wider rack configuration, as well as $\mathrm{T}_{\text {length }}$ shorter than $\mathrm{T}_{\text {height }}$ and in turn $\mathrm{b}$ lower than 1 , together with different access and retrieval probabilities. Another stream of research might be related to extending the study to assess travel times in triple shuttle systems. 


\section{References}

Azzi, A., Battini, D., Faccio, M., Persona, A., \& Sgarbossa, F. (2011). Innovative travel time model for dual-shuttle automated storage/retrieval systems. Computers \& Industrial Engineering, 61(3), 600607.

Bozer, Y. A., \& White, J. A. (1984). Travel-time models for automated storage/retrieval systems. IIE Transactions, 16(4), 329-338.

Cagliano, A. C., De Marco, A., \& Rafele, C. (2017). E-grocery supply chain management enabled by mobile tools. Business Process Management Journal, 23(1), 47-70.

Chang, D. T., Wen, U. P., \& Lin, J. T. (1995). The impact of acceleration/deceleration on travel-time models for automated storage/retrieval systems. IIE Transactions, 27(1), 108-111.

Choi, T. M., Yeung, W. K., \& Cheng, T. C. E. (2013). Scheduling and co-ordination of multi-suppliers single-warehouse-operator single-manufacturer supply chains with variable production rates and storage costs. International Journal of Production Research, 51(9), 2593-2601.

Cinar, D., Oliveira, J. A., Topcu, Y. I., \& Pardalos, P. M. (2017). Scheduling the truckload operations in automated warehouses with alternative aisles for pallets. Applied Soft Computing, 52, 566-574.

De Marco, A., \& Mangano, G. (2011). Relationship between logistic service and maintenance costs of warehouses. Facilities, 29(9/10), 411-421.

De Puy, G. W. (2007). Multiple shuttle AS/RS systems with acceleration/deceleration considerations. White Paper of Department of Industrial Engineering, University of Louisville.

Fukunari, M., \& Malmborg, C. J. (2008). An efficient cycle time model for autonomous vehicle storage and retrieval systems. International Journal of Production Research, 46(12), 3167-3184.

Gagliardi, J. P., Renaud, J., \& Ruiz, A. (2012). Models for automated storage and retrieval systems: a literature review. International Journal of Production Research, 50(24), 7110-7125.

Ghomri, L., \& Sari, Z. (2015). Mathematical modeling of retrieval travel time for flow-rack automated storage and retrieval systems. IFAC-Papers On Line, 48(3), 1906-1911.

Graves, S. C., Hausman, W. H., \& Schwarz, L. B. (1977). Storage-retrieval interleaving in automatic warehousing systems. Management Science, 23(9), 935-945.

Gu, J., Goetschalckx, M., \& McGinnis, L. F. (2010). Research on warehouse design and performance evaluation: A comprehensive review. European Journal of Operational Research, 203(3), 539-549.

Guo, S. M., \& Liu, T. P. (2008). Simulation Evaluation of Single Shuttle and Twin Shuttle AS/RS. International Journal of Electronic Business Management, 6(2), 106-115.

Hamzaoui, M. A., \& Sari, Z. (2015). Optimal dimensions minimizing expected travel time of a single machine flow rack AS/RS. Mechatronics, 31, 158-168.

Hausman, W. H., Schwarz, L. B., \& Graves, S. C. (1976). Optimal storage assignment in automatic warehousing systems. Management Science, 22(6), 629-638.

Hu, Y. H., Huang, S. Y., Chen, C., Hsu, W. J., Toh, A. C., Loh, C. K., \& Song, T. (2005). Travel time analysis of a new automated storage and retrieval system. Computers \& Operations Research, 32(6), $1515-1544$.

Hur, S., Lee, Y. H., Lim, S. Y., \& Lee, M. H. (2004). A performance estimation model for AS/RS by M/G/1 queuing system. Computers \& Industrial Engineering, 46(2), 233-241.

Hwang, H., \& Lee, S. B. (1990). Travel-time models considering the operating characteristics of the storage and retrieval machine. The International Journal of Production Research, 28(10), 1779- 1789.

Jaggi, C. K., Pareek, S., Khanna, A., \& Sharma, R. (2015). Two-warehouse inventory model for deteriorating items with price-sensitive demand and partially backlogged shortages under inflationary conditions. International Journal of Industrial Engineering Computations, 6(1), 59-80.

Jansen, D. R., Van Weert, A., Beulens, A. J., \& Huirne, R. B. (2001). Simulation model of multicompartment distribution in the catering supply chain. European Journal of Operational Research, 133(1), 210-224.

Jindal, P., \& Solanki, A. (2016). Integrated supply chain inventory model with quality improvement involving controllable lead time and backorder price discount. International Journal of Industrial Engineering Computations, 7(3), 463-480. 
Keserla, A., \& Peters, B. A. (1994). Analysis of dual-shuttle automated storage/retrieval systems. Journal of Manufacturing Systems, 13(6), 424-434.

Lerher, T., Ekren, B. Y., Dukic, G., \& Rosi, B. (2015). Travel time model for shuttle-based storage and retrieval systems. The International Journal of Advanced Manufacturing Technology, 78(9-12), 1705-1725.

Lerher, T., Potrč, I., Šraml, M., \& Tollazzi, T. (2010a). Travel time models for automated warehouses with aisle transferring storage and retrieval machine. European Journal of Operational Research, 205(3), 571-583.

Lerher, T., Šraml, M., \& Potrč, I. (2011). Simulation analysis of mini-load multi-shuttle automated storage and retrieval systems. The International Journal of Advanced Manufacturing Technology, 54(1-4), 337-348.

Lerher, T., Sraml, M., Potrc, I., \& Tollazzi, T. (2010b). Travel time models for double-deep automated storage and retrieval systems. International Journal of Production Research, 48(11), 3151-3172.

Ma, H., Su, S., Simon, D., \& Fei, M. (2015). Ensemble multi-objective biogeography-based optimization with application to automated warehouse scheduling. Engineering Applications of Artificial Intelligence, 44, 79-90.

Meller, R. D., \& Mungwattana, A. (1997). Multi-shuttle automated storage/retrieval systems. IIE transactions, 29(10), 925-938.

Montgomery, D. C., \& Runger, G. C. (2010). Applied statistics and probability for engineers. John Wiley \& Sons.

Oser, J., \& Garlock, P. (1998). Technology and Throughput of Double-Deep Multi-Shuttle AS/RS. Progress in Material Handling Research, 5, 409-423.

Oser, J., \& Ritonja, M. (2004). Expected Cycle Time in a Class-Based Single- and Double-Deep Storage System. In Progress in Material Handling Research (pp. 357-371). Charlotte, NC 28217, USA: The Material Handling Industry of America.

Peters, B. A., Smith, J. S., \& Hale, T. S. (1996). Closed form models for determining the optimal dwell point location in automated storage and retrieval systems. International Journal of Production Research, 34(6), 1757-1771.

Potrč, I., Lerher, T., Kramberger, J., \& Šraml, M. (2004). Simulation model of multi-shuttle automated storage and retrieval systems. Journal of Materials Processing Technology, 157-158, 236-244.

Rabbani, M., Monshi, M., Manavizadeh, N., \& Jalali, M.S. (2016). Designing an advanced available-topromise mechanism compatible with the make-to-forecast production systems through integrating inventory allocation and job shop scheduling with due dates and weighted earliness/tardiness cost. International Journal of Industrial Engineering Computations, 7(3), 451-462.

Roodbergen, K. J., \& Vis, I. F. (2009). A survey of literature on automated storage and retrieval systems. European Journal of Operational Research, 194(2), 343-362.

Sarker, B. R., \& Babu, P. S. (1995). Travel time models in automated storage/retrieval systems: A critical review. International Journal of Production Economics, 40(2-3), 173-184.

Schwarz, L. B., Graves, S. C., \& Hausman, W. H. (1978). Scheduling policies for automatic warehousing systems: simulation results. AIIE Transactions, 10(3), 260-270.

Tukey, J. W. (1977). Exploratory data analysis (Vol. 2). Reading, MA: Addison-Wesley.

Wen, U. P., Chang, D. T., \& Chen, S. P. (2001). The impact of acceleration/deceleration on travel-time models in class-based automated S/R systems. IIE Transactions, 33(7), 599-608.

Xu, X., Shen, G., Yu, Y., \& Huang, W. (2015). Travel time analysis for the double-deep dual-shuttle AS/RS. International Journal of Production Research, 53(3), 757-773.

Yang, P., Miao, L., Xue, Z., \& Ye, B. (2015). Variable neighborhood search heuristic for storage location assignment and storage/retrieval scheduling under shared storage in multi-shuttle automated storage/retrieval systems. Transportation Research Part E: Logistics and Transportation Review, 79, $164-177$.

Yu, Y., \& De Koster, M. B. M. (2009). Designing an optimal turnover-based storage rack for a 3D compact automated storage and retrieval system. International Journal of Production Research, 47(6), 1551-1571. 


(C) 2019 by the authors; licensee Growing Science, Canada. This is an open access article
distributed under the terms and conditions of the Creative Commons Attribution (CC-
BY) license (http://creativecommons.org/licenses/by/4.0/).

